\title{
Synthesis and characterization of composites of mixed oxides of iron and neodymium in polymer matrix of aniline-formaldehyde
}

\author{
SAJDHA, H N SHEIKH*, B L KALSOTRA, N KUMAR ${ }^{\dagger}$ and S KUMAR ${ }^{\dagger \dagger}$ \\ Department of Chemistry, University of Jammu, Jammu 180 006, India \\ ${ }^{\dagger}$ Defence Laboratory, Jodhpur, India \\ ${ }^{\dagger}$ DRDO, New Delhi, India
}

MS received 18 September 2009; revised 26 January 2010

\begin{abstract}
Nanocomposites of mixed oxides of iron and neodymium in polymer matrix of anilineformaldehyde are reported. The composites have been obtained by treating the aqueous solution of aniline, hydrochloric acid and formaldehyde with halide of iron and neodymium oxide. The infra-red spectra show broad peaks at $\sim 590 \mathrm{~cm}^{-1}$ and at $\sim 610 \mathrm{~cm}^{-1}$ due to the presence of oxides of both iron and neodymium. In heated samples, the absorption peaks due to metal oxides are better resolved. A broad and strong peak in XRD spectra at $2 \theta$ value of 35.69920 corresponds to spinel $\gamma-\mathrm{Fe}_{2} \mathrm{O}_{3} .{ }^{57} \mathrm{Fe}$ Mössbauer spectrum for unheated sample gives Mössbauer parameters, i.e. isomer shift $(\delta)$, quadrupole splitting $(\Delta E)$ and effective magnetic field $\left(\mathrm{H}_{\text {eff }}\right)$. Transmission electron microscopy (TEM) micrographs reveal well dispersed particles at different magnifications. Vibrating sample magnetometry (VSM) studies indicate that the ferrite nanoparticles exhibit characteristics of ferromagnetism.
\end{abstract}

Keywords. Nanocomposites; polymer matrix; neodymium oxide; spinel ferrites; quadrupole splitting; Scherrer equation.

\section{Introduction}

In the past few years, nanocomposite materials have become one of the most extensively studied materials all over the world as they have shown several applications such as in quantum electronic devices, magnetic recording materials, sensors, etc (Anderson et al 1994; Sinfelt 1977).

Moreover, nanocomposite materials composed of oxides and conducting polymers have brought out more fields of applications such as smart windows, toners in photocopying, conductive paints, drug delivery, rechargeable batteries, etc (Maeda and Armes 1994; Butterworth et al 1995; Jarjayes et al 1995; Suri et al 2001). Many of the attributes that influence structure-property relationships for a polymer such as molecular weight, chain length, architecture, ordering and functional groups have been explored. The size of polymer makes them convenient for use as nanostructured materials, and they are also useful as a scaffold to orient and arrange other nanomaterials to produce nanocomposites with enhanced properties.

The nanocomposites formed by combining organic polymer and inorganic nanoparticles (viz. oxides) possess all the good properties of both the constituents and an enhanced utility thereof and hence, constitute a relatively new and unique area in material science. By combining at

*Author for correspondence (hnsheikh@rediffmail.com) the molecular level inorganic and organic polymer material, a blending of unique physical properties can be achieved. Magnetic ferrites having hexagonal/cubical symmetry belong to the magneto-plumbite group of oxides and find application in high density recording media, microwave devices and in many magnetically operated devices such as magnetic levitations, telephone ringers and receivers, etc (Viswanathan 1990; Bahadur 1992; Kladnig and Zenger 1992). An interesting chemical route (Pramanik 1995) has been reported to prepare nanoparticles of inorganic oxides by using polymeric materials.

The present work reports the in situ direct synthesis of nanocomposites by employing mixed oxides of iron and neodymium in co-polymer matrix of aniline-formaldehyde at room temperature.

\section{Experimental}

In the present work, we report the synthesis of a series of nanocomposites of neodymium ferrites in the co-polymer matrix of aniline-formaldehyde.

\subsection{Synthesis of nanocomposites in different stoichiometric ratio}

Nanocomposites of neodymium ferrites in a co-polymer matrix were synthesized by using the direct room tempe- 
rature chemical method (Vadera et al 1997b). Five different nanocomposites were synthesized by taking ferric chloride and neodymium oxide in different stoichiometric ratios given in table 1 along with the monomers to form the copolymer. In a typical preparation, sample ND1 was synthesized by mixing the aqueous solutions of aniline $(0.027 \mathrm{~mol})$, hydrochloric acid $(0.1 \mathrm{~mol})$ and formaldehyde $(0.09 \mathrm{~mol})$ and the chloride of iron and neodymium oxide taken according to the stoichiometry. The resulting solution was stirred thoroughly and added to a $10 \%$ solution of sodium hydroxide. The precipitated composite was filtered and washed repeatedly with distilled water till the filtrate was free of alkali and then dried in air. Similarly, the samples ND2-ND5 were synthesized by taking $\mathrm{Nd}$ and $\mathrm{Fe}$ in different stoichimetric ratios.

The samples ND1-ND5 were heated to $4500^{\circ} \mathrm{C}$ and $7000^{\circ} \mathrm{C}$ in a furnace under a restricted supply of air to obtain samples ND6-ND10 and ND11-ND15 respectively.

\subsection{Synthesis of nanocomposites in presence of different oxidants}

The nanocomposites of neodymium ferrites were synthesized in a co-polymer matrix of aniline-formaldehyde using a synthetic route (Sharma et al 2003). As a typical preparation, sample NT1 was synthesized by mixing the aqueous solution of aniline $(0.027 \mathrm{~mol})$, hydrochloric acid $(0.1 \mathrm{~mol})$, formaldehyde $(0.09 \mathrm{~mol})$ and ferric chloride and neodymium oxide taken in a fixed molar ratio. To this quinolinium chlorochromate $(0.008 \mathrm{~mol})$ was added as an oxidant. The resulting solution was stirred thoroughly and added to a $10 \%$ solution of sodium hydroxide. The precipitated composite was filtered and washed repeatedly with distilled water till the filtrate was free of alkali $(\mathrm{pH} 7)$ and then dried in air.

Similarly, the samples NT2-NT7 were synthesized following the similar procedure by using different oxidants (potassium permanganate, morpholinium chlorochromate, pyridinium chlorochromate, potassium dichromate, isoquinolinium chlorochromate, piperidinium chlorochromate). The compositional details of the samples NT1 to NT7 are given in table 2. The samples NT1 to NT7 were heated in a furnace under a restricted supply of air to $4500^{\circ} \mathrm{C}$ and $7000^{\circ} \mathrm{C}$ to obtain samples NT8 to NT14 and NT15 to NT21, respectively.

Table 1. Reaction conditions for the synthesis of as-prepared samples ND1-ND5.

\begin{tabular}{lcc}
\hline Sample & Conc. of $\mathrm{FeCl}_{3}(\mathrm{~mol})$ & Conc. of $\mathrm{Nd}_{2} \mathrm{O}_{3}(\mathrm{~mol})$ \\
\hline ND1 & 0.01 & 0.005 \\
ND2 & 0.015 & 0.005 \\
ND3 & 0.02 & 0.005 \\
ND4 & 0.025 & 0.005 \\
ND5 & 0.03 & 0.005 \\
\hline
\end{tabular}

\section{Characterization of nanocomposites}

The nanocomposites were characterized by FTIR spectroscopy, X-ray diffraction, ${ }^{57} \mathrm{Fe}$ Mössbauer spectroscopy, scanning electron microscopy, energy dispersive X-ray analysis (EDAX), transmission electron microscopy (TEM) and vibrating sample magnetometry (VSM) studies.

\subsection{Infrared spectra}

The characteristic IR spectral bands of the nanocomposites ND1-ND5 in the frequency range $2000-400 \mathrm{~cm}^{-1}$ are presented in table 3 . The absorption peak due to polymer part of the samples (Mathur et al 1999a) are observed in the frequency range $2000-800 \mathrm{~cm}^{-1}$ while the absorption peak around 578 and $427 \mathrm{~cm}^{-1}$ can be attributed to the presence of neodymium ferrite (Li et al 1998). Vadera et al (1997a) have reported a similar IR spectrum of nanocomposite of spinel $\alpha-\mathrm{Fe}_{2} \mathrm{O}_{3}$ in a co-polymer matrix. Further, the comparison of IR spectra of the samples ND1-ND5 shows that the peak due to neodymium ferrite broadens with increasing concentration of Fe from samples ND1-ND5 which may be attributed to decrease in size of magnetic particles (Mathur et al 1999b). In the IR spectra of the samples ND6-ND10 (heated to $4500^{\circ} \mathrm{C}$ ) (table 3 ), the absorption peak at $575 \mathrm{~cm}^{-1}$ is observed due to neodymium ferrite phase. The peaks due to polymer part disappear as most of the organic part burns away at $4500^{\circ} \mathrm{C}$. The shifting of the peak position $\sim 575 \mathrm{~cm}^{-1}$ due to neodymium ferrite in samples ND6-ND10 may be attributed to the increase in their particle size. IR bands of samples ND11-ND15 heated to $7000^{\circ} \mathrm{C}$ are given in table 3 . The IR spectrum of sample ND12 shows peak at $560 \mathrm{~cm}^{-1}$ thereby indicating that both $\alpha-\mathrm{Fe}_{2} \mathrm{O}_{3}$ and neodymium ferrite coexist in the sample (Mathur et al 1999b).

The IR spectra of the nanocomposites NT1-NT7 (table 4) show strong absorption around 580 and $428 \mathrm{~cm}^{-1}$ due to neodymium ferrite (Sharma et al 2003). The possibility of $\alpha-\mathrm{FeOOH}$ is ruled out due to the absence of its characteristic absorption at $800 \mathrm{~cm}^{-1}$ and $890 \mathrm{~cm}^{-1}$ (Koch et al 1986). The absorption bands observed at 815 and $510 \mathrm{~cm}^{-1}$ are due to presence of the co-polymer (Mathur et al 1998). It is evident that for the as-prepared nanocomposites NT1-NT7, absorption peak around $600 \mathrm{~cm}^{-1}$ is due to tetrahedrally coordinated metal ion in spinel ferrites (Josyulu and Sobhanadri 1981). This peak may be attributed to the presence of oxides of both iron and neodymium in these samples (Li et al 1998). In case of the samples heated to $4500^{\circ} \mathrm{C}$ (table 4 ), the polymer part is burnt and only the absorption peaks due to metal oxides are found. In the samples NT8-NT14, containing iron and neodymium, absorption peaks at around $590-570 \mathrm{~cm}^{-1}$ and $495-470 \mathrm{~cm}^{-1}$ are due to $\gamma-\mathrm{Fe}_{2} \mathrm{O}_{3}$ and neodymium 
Table 2. Reaction conditions for the synthesis of as-prepared samples NT1-NT7.

\begin{tabular}{lcclc}
\hline Sample & Conc. of $\mathrm{FeCl}_{3}(\mathrm{~mol})$ & Conc. of $\mathrm{Nd}_{2} \mathrm{O}_{3}(\mathrm{~mol})$ & \multicolumn{1}{c}{ Oxidant used } & Conc. of the oxidant \\
\hline NT1 & $0 \cdot 15$ & 0.005 & Potassium dichromate & $0 \cdot 009$ \\
NT2 & $0 \cdot 15$ & 0.005 & Potassium permanganate & $0 \cdot 019$ \\
NT3 & $0 \cdot 15$ & 0.005 & Morpholinium chlorochromate & $0 \cdot 010$ \\
NT4 & $0 \cdot 15$ & 0.005 & Quinolinium chlorochromate & $0 \cdot 008$ \\
NT5 & $0 \cdot 15$ & 0.005 & Isoquinolinium chlorochromate & $0 \cdot 008$ \\
NT6 & $0 \cdot 15$ & 0.005 & Pyridinium chlorochromate & 0.013 \\
NT7 & $0 \cdot 15$ & 0.005 & Piperidinium chlorochromate & $0 \cdot 010$ \\
\hline
\end{tabular}

Table 3. IR bands $\left(\mathrm{cm}^{-1}\right)$ of nanocomposites prepared in different stoichiometric ratios.

\begin{tabular}{|c|c|c|c|c|c|}
\hline Sample & $\begin{array}{c}\text { Peaks of as } \\
\text { prepared samples }\end{array}$ & Sample & $\begin{array}{l}\text { Peaks of samples } \\
\text { heated to } 450^{\circ} \mathrm{C}\end{array}$ & Sample & $\begin{array}{l}\text { Peaks of samples } \\
\text { heated to } 700^{\circ} \mathrm{C}\end{array}$ \\
\hline ND1 & $\begin{array}{c}1634 \cdot 6 \\
1517 \cdot 4 \\
1462 \cdot 3 \\
745 \cdot 1\end{array}$ & ND6 & $\begin{array}{l}867 \cdot 1 \\
689 \cdot 6 \\
536 \cdot 1\end{array}$ & ND11 & $\begin{array}{l}534.0 \\
485 \cdot 2\end{array}$ \\
\hline ND2 & $\begin{array}{c}1635.8 \\
1576 \cdot 5 \\
1555 \cdot 0 \\
816 \cdot 3\end{array}$ & ND7 & $\begin{array}{l}856 \cdot 8 \\
565 \cdot 8 \\
445 \cdot 5\end{array}$ & ND12 & $\begin{array}{l}590.1 \\
474 \cdot 0\end{array}$ \\
\hline ND3 & $\begin{array}{c}1685 \cdot 6 \\
1572 \cdot 9 \\
743 \cdot 3 \\
668 \cdot 7\end{array}$ & ND8 & $\begin{array}{l}604.1 \\
585 \cdot 5 \\
549 \cdot 7\end{array}$ & ND13 & $\begin{array}{l}556 \cdot 8 \\
467 \cdot 0\end{array}$ \\
\hline ND4 & $\begin{array}{c}1675 \cdot 6 \\
1666 \cdot 3 \\
624 \cdot 3 \\
556 \cdot 4\end{array}$ & ND9 & $\begin{array}{l}723 \cdot 1 \\
638 \cdot 4 \\
554 \cdot 5\end{array}$ & ND14 & $\begin{array}{l}545 \cdot 3 \\
463 \cdot 0\end{array}$ \\
\hline ND5 & $\begin{array}{c}1637 \cdot 4 \\
1543 \cdot 3 \\
625 \cdot 2 \\
423 \cdot 0\end{array}$ & ND10 & $\begin{array}{l}765 \cdot 3 \\
556 \cdot 5 \\
424 \cdot 4\end{array}$ & ND15 & $\begin{array}{l}556 \cdot 0 \\
472 \cdot 3\end{array}$ \\
\hline
\end{tabular}

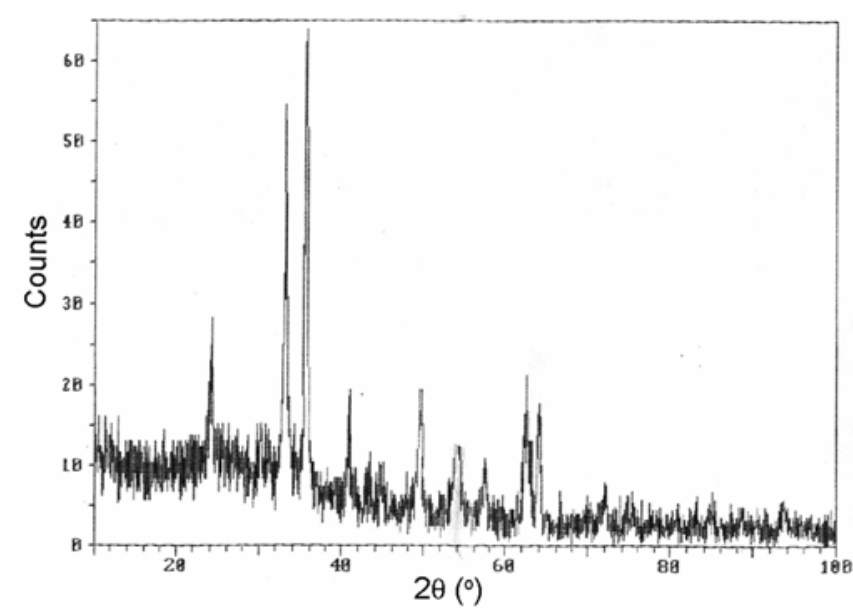

Figure 1. XRD spectra of sample ND7.

ferrite phase respectively ( $\mathrm{Li}$ et al 1998). Further, variations in absorption peak due to iron oxide, in samples
NT8-NT14, may be attributed to varying degrees of interactions between $\mathrm{Fe}$ and $\mathrm{Nd}$ ions which in turn might be a consequence of the changes in polymer backbone by different oxidative environment, in the initial samples. From the IR spectra of samples heated to $7000^{\circ} \mathrm{C}$, further broadening of the metal oxide peaks is observed in samples NT15-NT21. This behaviour may arise because of the increased solubility of neodymium oxide in $\gamma-\mathrm{Fe}_{2} \mathrm{O}_{3}$ due to their small size effects (Johnson and Alexander 1986). A very broad peak at $555 \mathrm{~cm}^{-1}$ indicates that both $\alpha-\mathrm{Fe}_{2} \mathrm{O}_{3}$ and neodymium ferrite coexist in the samples (Mathur et al 1999b).

\section{$3.2 X$-ray diffraction}

X-ray diffraction spectra (XRD) of sample ND7 heated to $4500^{\circ} \mathrm{C}$ is shown in figure 1 . It is seen that the lines for the heated samples are narrow and intense which indicates that on heating the nanocomposites, the 
Table 4. IR bands $\left(\mathrm{cm}^{-1}\right)$ of nanocomposites prepared in presence of different oxidants.

\begin{tabular}{|c|c|c|c|c|c|}
\hline Sample & $\begin{array}{c}\text { Peaks of as } \\
\text { prepared samples }\end{array}$ & Sample & $\begin{array}{l}\text { Peaks of samples } \\
\text { heated to } 450^{\circ} \mathrm{C}\end{array}$ & Sample & $\begin{array}{l}\text { Peaks of samples } \\
\text { heated to } 700^{\circ} \mathrm{C}\end{array}$ \\
\hline NT1 & $\begin{array}{c}1712.1 \\
1523.4 \\
1423.3 \\
815.1\end{array}$ & NT8 & $\begin{array}{l}723.3 \\
578.0\end{array}$ & NT15 & $\begin{array}{l}523.1 \\
444.2\end{array}$ \\
\hline NT2 & $\begin{array}{c}1665.5 \\
1592.5 \\
1565.0 \\
877.3 \\
487.8\end{array}$ & NT9 & $\begin{array}{c}1566.8 \\
1458.5 \\
765.6 \\
569.0 \\
526.6\end{array}$ & NT16 & $\begin{array}{l}543.5 \\
445.2\end{array}$ \\
\hline NT3 & $\begin{array}{c}1764.6 \\
1556.9 \\
871.3 \\
669.7\end{array}$ & NT10 & $\begin{array}{c}1663.1 \\
635.5 \\
565.8 \\
465.6\end{array}$ & NT17 & $\begin{array}{l}562.8 \\
456.2\end{array}$ \\
\hline NT4 & $\begin{array}{c}1666.6 \\
1622.3 \\
1612.3 \\
512.4\end{array}$ & NT11 & $\begin{array}{c}1532.1 \\
882.4 \\
569.5 \\
479.3\end{array}$ & NT18 & $\begin{array}{l}568.3 \\
445.0\end{array}$ \\
\hline NT5 & $\begin{array}{c}1633.4 \\
1534.3 \\
862.2 \\
412.0\end{array}$ & NT12 & $\begin{array}{c}1766.3 \\
571.2 \\
775.2 \\
423.2\end{array}$ & NT19 & $\begin{array}{l}561.2 \\
437.1\end{array}$ \\
\hline NT6 & $\begin{array}{c}1563.1 \\
1463.0 \\
689.2 \\
542.3\end{array}$ & NT13 & $\begin{array}{c}1657.2 \\
1475.2 \\
764.3 \\
554.8\end{array}$ & NT20 & $\begin{array}{l}576.8 \\
438.1\end{array}$ \\
\hline NT7 & $\begin{array}{c}1676.2 \\
1575.4 \\
1578.9 \\
539.1\end{array}$ & NT14 & $\begin{array}{c}1607.5 \\
1577.4 \\
813.6 \\
774.3\end{array}$ & NT21 & $\begin{array}{l}557.1 \\
442.5\end{array}$ \\
\hline
\end{tabular}

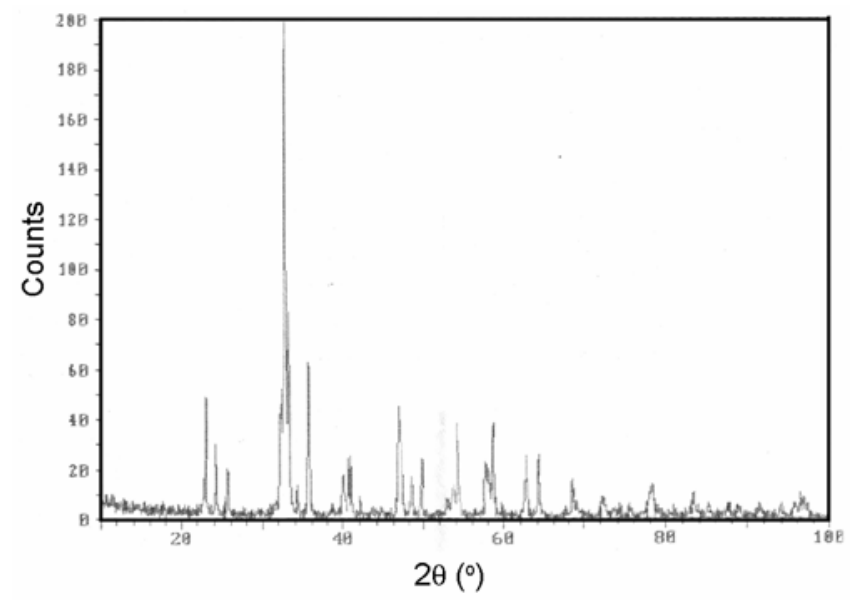

Figure 2. XRD spectra of sample ND13.

inorganic component still remains unchanged in terms of its structure, i.e. it is still neodymium ferrite but with an increase in particle size. A very broad peak in case of samples ND7 and ND8 at $2 \theta$ value of 35.69920 corre- sponds to the strongest diffraction peak due to spinel $\gamma-\mathrm{Fe}_{2} \mathrm{O}_{3}$ and neodymium ferrite. The estimated particle size calculated by using Scherrer equation (Suryanarayana and Norton 1996) lies in the range 10-16 nm as given in table 5 .

$$
B=K \lambda / L \cos \theta,
$$

where $\beta$ is the broadening of the line in terms of angle $(2 \theta), K$ is the constant (taken as 1$), L$ is the average length of the crystallite, $\lambda$ is the wavelength of the X-rays and $\theta$ is the angle of diffraction.

The XRD spectra of the samples ND11-ND15 heated to $7000^{\circ} \mathrm{C}$ show very interesting behaviour. As can be seen from figure 2 , in case of ND13, the diffraction peak at $2 \theta$ value of about 25.69930 corresponds to $\alpha-\mathrm{Fe}_{2} \mathrm{O}_{3}$ phase (Mathur et al 1999b) while in sample ND13, increase in intensity of diffraction pattern due to $\mathrm{Nd}-\mathrm{Fe} / \alpha$ $\mathrm{Fe}_{2} \mathrm{O}_{3}$ phase is observed. The calculations suggest that the average size in these samples range from $14-27 \mathrm{~nm}$ as given in table 5 .

From the XRD studies, it is seen that the metal oxides in unheated samples NT1-NT7 were amorphous while on 
heating at temperatures $>3000^{\circ} \mathrm{C}$, the samples were crystalline in nature. The sample on heating to $4500^{\circ} \mathrm{C}$ in air for one hour mostly contain inorganic part as almost all the organic part has burnt away at this temperature. The observed diffraction peaks were indexed to identify different phases present in the samples. In the XRD spectrum of sample NT11, a broad peak at $2 \theta$ value of 35.77550 corresponds to the strongest diffraction peak due to $\gamma-\mathrm{Fe}_{2} \mathrm{O}_{3}$ and $\mathrm{Nd}-\mathrm{Fe}$ phase respectively (figure 3 ). The estimated particle size as calculated by using Scherrer equation is $17 \mathrm{~nm}$ as shown in table 6 .

The XRD spectrum of the sample NT18 heated to $7000^{\circ} \mathrm{C}$ is shown in figure 4 . From the figure, a strong diffraction peak at $2 \theta$ value of 33.22340 corresponds to $\alpha-\mathrm{Fe}_{2} \mathrm{O}_{3}$ phase. A prominent peak corresponding to $\mathrm{Nd}-$

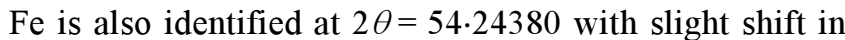

Table 5. Crystallite size of nanocomposites in different stoichiometric ratios.

\begin{tabular}{lccc}
\hline Sample & $\begin{array}{c}\text { Crystallite } \\
\text { size }(\mathrm{nm})\end{array}$ & Sample & $\begin{array}{c}\text { Crystallite } \\
\text { size }(\mathrm{nm})\end{array}$ \\
\hline ND6 & 14 & ND11 & 17 \\
ND8 & $12 \cdot 6$ & ND13 & 19 \\
ND10 & 9 & ND14 & $21 \cdot 9$ \\
\hline
\end{tabular}

Table 6. Crystallite size of nanocomposites in presence of different oxidants

\begin{tabular}{lclc}
\hline Sample & $\begin{array}{c}\text { Crystallite } \\
\text { size }(\mathrm{nm})\end{array}$ & Sample & $\begin{array}{c}\text { Crystallite } \\
\text { size }(\mathrm{nm})\end{array}$ \\
\hline NT9 & 15 & NT16 & $16 \cdot 30$ \\
NT11 & $11 \cdot 4$ & NT18 & $22 \cdot 4$ \\
NT13 & $10 \cdot 9$ & NT21 & $26 \cdot 3$ \\
\hline
\end{tabular}

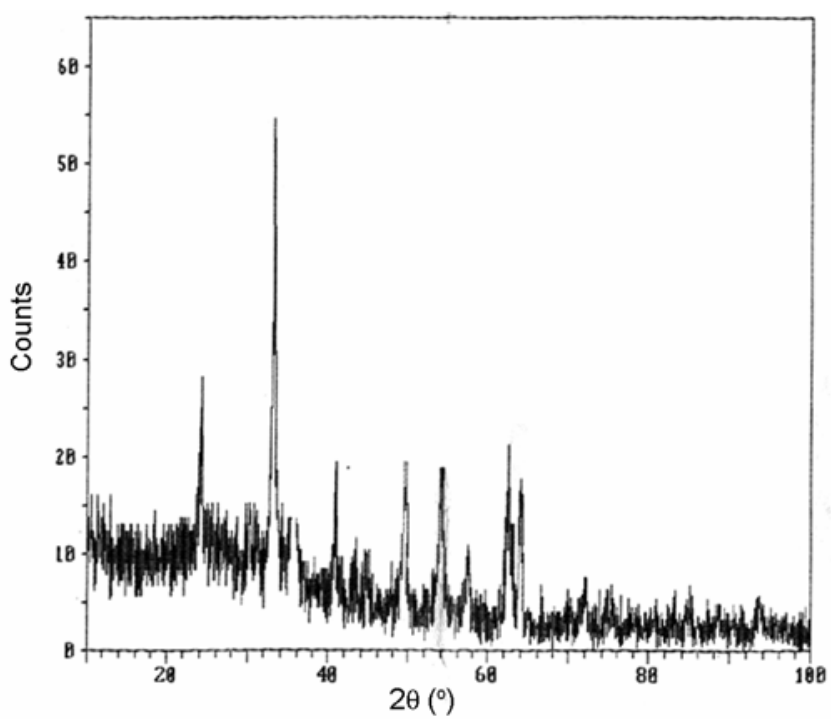

Figure 3. XRD spectra of sample NT11. case of sample NT15 (Li et al 1998; Mathur et al 1999b). The calculations suggest that the average particle size in the samples is $31 \mathrm{~nm}$ as given in table 6 .

The above studies show that in unheated samples, the formation of $\gamma-\mathrm{Fe}_{2} \mathrm{O}_{3}$, takes place at room temperature which on heating to $7000^{\circ} \mathrm{C}$ transforms into $\alpha-\mathrm{Fe}_{2} \mathrm{O}_{3}$. The studies also show that the extent of reduction in the intensity of diffraction due to $\mathrm{Nd}-\mathrm{Fe}$ phase is greatly influenced by varying the nature of the oxidative environments present during the preparation of initial samples and its solubility behaviour.

\section{$3.3 \quad{ }^{57} \mathrm{Fe}$ Mössbauer spectroscopy}

Room temperature ${ }^{57} \mathrm{Fe}$ Mössbauer spectrum was taken for unheated sample ND5 (figure 5). The values of the computed Mössbauer parameters for the sample ND5 are given in table 7 . Fitting of the spectral data, by assuming the lines to be lorentzian in shape, given in figure, shows the presence of two sextets corresponding to magnetically

Table 7. Mössbauer parameters for the magnetic particles of iron/neodymium oxides in copolymer matrix of anilineformaldehyde.

Sample

\begin{tabular}{lrrrr}
\hline Sextet I & 362 & -0.08 & $0 \cdot 19$ & 0.60 \\
Sextet II & 483 & -0.39 & 0.25 & $0 \cdot 10$ \\
Doublet & - & 0.77 & 0.24 & 0.30
\end{tabular}

Isomeric shift values are with respect to natural iron

Table 8. Mössbauer parameters for the magnetic particles of iron/neodymium oxides in copolymer matrix of anilineformaldehyde in presence of oxidant potassium dichromate.

Sample Hhf $(\mathrm{kOe}) \quad$ QS $(\mathrm{mm} / \mathrm{s}) \quad$ IS $(\mathrm{mm} / \mathrm{s}) \quad$ WV $(\mathrm{mm} / \mathrm{s})$

\begin{tabular}{lllll}
\hline NT1 & - & 0.56 & 0.22 & 0.42 \\
\hline
\end{tabular}

Isomeric shift values are with respect to natural iron

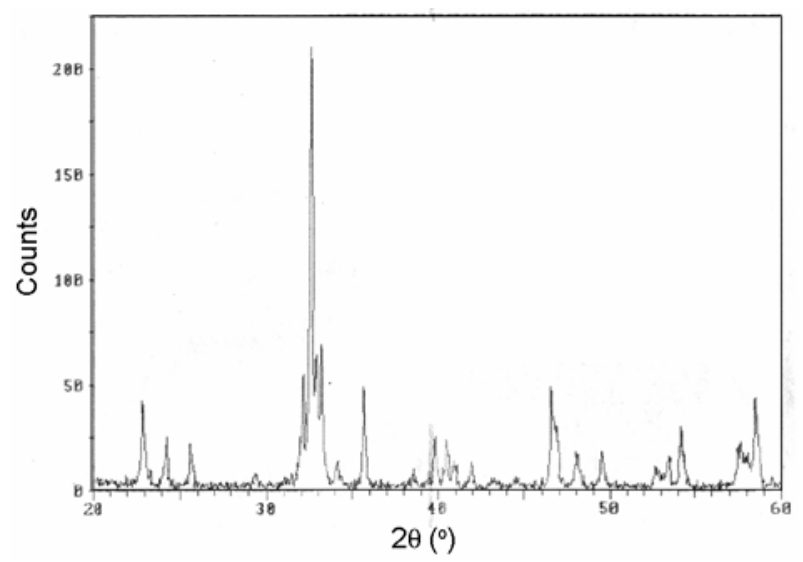

Figure 4. XRD spectra of sample NT18. 
ordered phase. The six-line pattern could be resolved into two sextets with Heff values which correspond to the presence of $\alpha-\mathrm{Fe}_{2} \mathrm{O}_{3}$ (Vadera et al 1997a). However, the relaxed nature of the spectrum indicates that the size of the magnetic particles is in the critical nanometer range.

Room temperature ${ }^{57} \mathrm{Fe}$ Mössbauer spectrum was recorded for unheated sample NT1 (figure 6). The Mössbauer parameters calculated from the computer fitted spectral data for the sample NT1 are given in table 8 . A single quadrupole doublet due to $\mathrm{Fe}^{3+}$ ions is observed. The higher values of QS as compared to bulk iron are a clear indication of the particles being in nanometer range (Greenwood and Gibb 1971). The presence of quadrupole doublet indicates the presence of paramagnetic/superparamagnetic phase for which Heff value is zero which shows the presence of very small sized particles of neodymium ferrite (Matutes- Aquino et al 2000).

\subsection{Scanning electron microscopy and energy dispersive $X$-ray analysis (EDAX)}

Figure 7 shows SEM micrograph of the unheated sample ND3. SEM micrograph of neodymium ferrite shows well

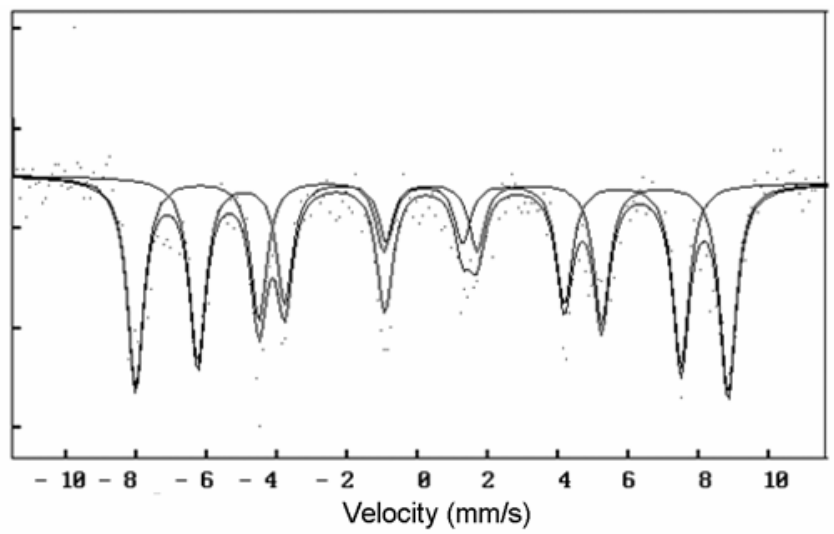

Figure 5. Room temperature Mossbauer spectra of sample ND5.

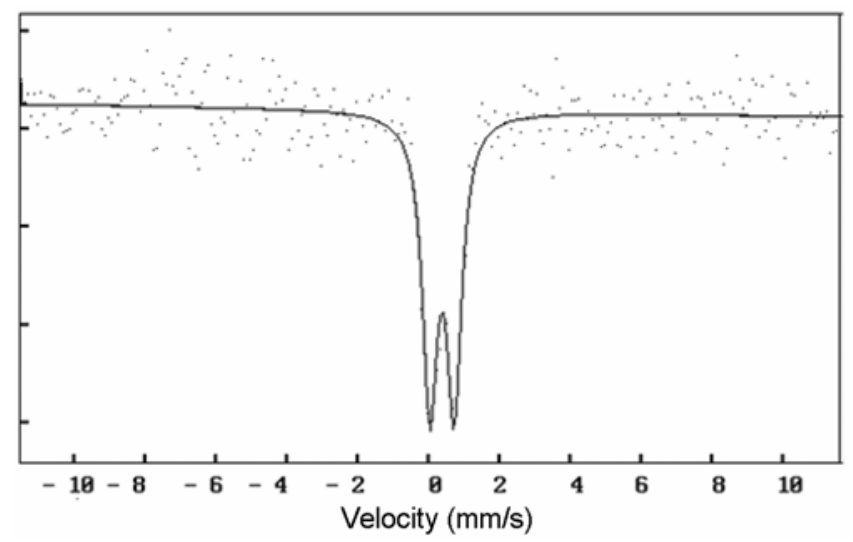

Figure 6. Room temperature Mössbauer spectra of sample NT1. dispersed particles at different magnifications (Li et al 1998). In some portions of the image, agglomerated spherical particles are seen perhaps due to their magnetic nature. The particles vary in size and dimensions showing composite nature which is observed in X-ray diffraction.

Figure 8 shows the SEM micrograph of the sample NT5. It is seen that particles vary in size and

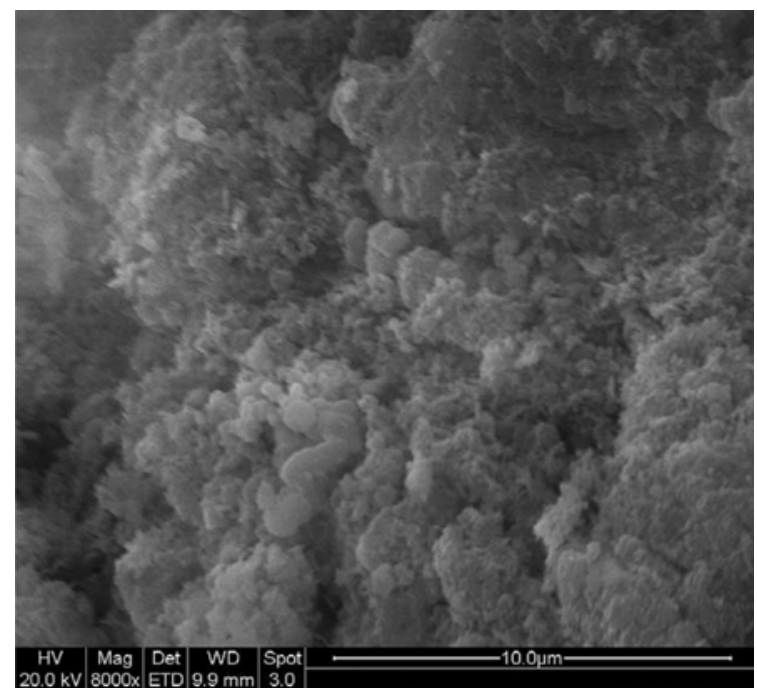

Figure 7. SEM image of sample ND3.

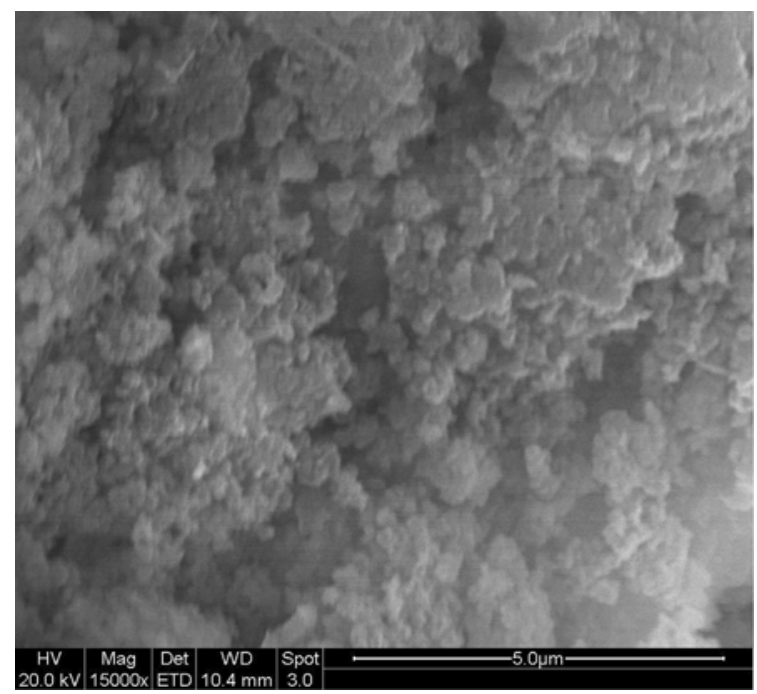

Figure 8. SEM image of sample NT5.

Table 9. EDAX results: concentration of different elements in prepared sample ND3.

\begin{tabular}{lcc}
\hline Element & $\mathrm{Wt} \%$ & At\% \\
\hline $\mathrm{CK}$ & 67.38 & 79.06 \\
$\mathrm{NK}$ & 09.44 & 09.50 \\
$\mathrm{OK}$ & 10.51 & 09.26 \\
$\mathrm{ClK}$ & 00.69 & 00.27 \\
$\mathrm{FeK}$ & 04.78 & 01.21 \\
NdL & 07.20 & 00.70 \\
Matrix & Correction & ZAF \\
\hline
\end{tabular}


dimensions showing composite nature which is observed in the X-ray diffraction. They are surrounded by an oxidant layer which separates them from each other and prevents aggregation and exhibits rough surface of composites.

Figures 9 and 10 show the corresponding EDAX spectra of samples ND3 and NT5, which indicate the presence of only iron, neodymium, chlorine and oxygen. It

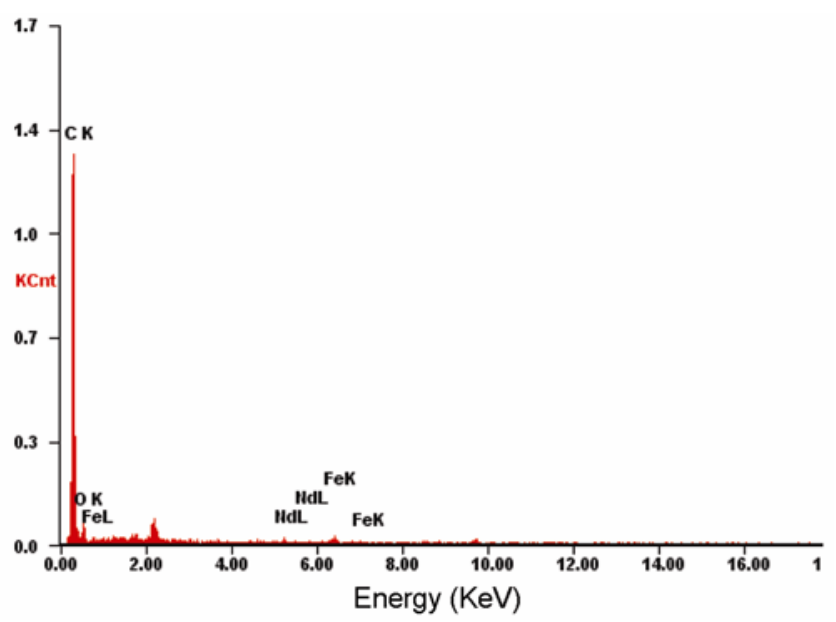

Figure 9. EDAX image of sample ND3.

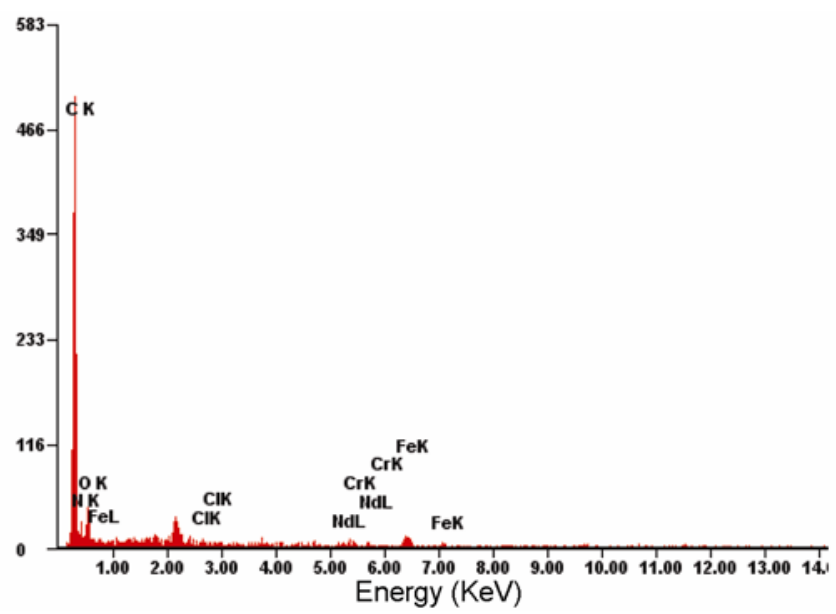

Figure 10. EDAX image of sample NT5.

Table 10. EDAX results: concentration of different elements in prepared samples NT5.

\begin{tabular}{lrl}
\hline Element & $\mathrm{Wt} \%$ & $\mathrm{At} \%$ \\
\hline $\mathrm{CK}$ & $66 \cdot 34$ & $79 \cdot 00$ \\
$\mathrm{NK}$ & $8 \cdot 04$ & $09 \cdot 50$ \\
$\mathrm{OK}$ & $9 \cdot 51$ & $08 \cdot 36$ \\
$\mathrm{ClK}$ & $00 \cdot 69$ & $00 \cdot 27$ \\
$\mathrm{CrK}$ & $03 \cdot 40$ & $01 \cdot 16$ \\
$\mathrm{FeK}$ & 04.28 & $01 \cdot 25$ \\
NdL & $07 \cdot 35$ & $00 \cdot 73$ \\
Matrix & Correction & ZAF \\
\hline
\end{tabular}

is observed that the atomic percentage of neodymium is less than that of iron and oxygen as shown in tables 9 and 10. The sample NT5 shows the presence of chromium as an impurity from the oxidant.

\subsection{Transmission electron microscopy}

TEM micrograph of the sample NT5 is shown in figure 11. From the micrograph it is evident that the mixed

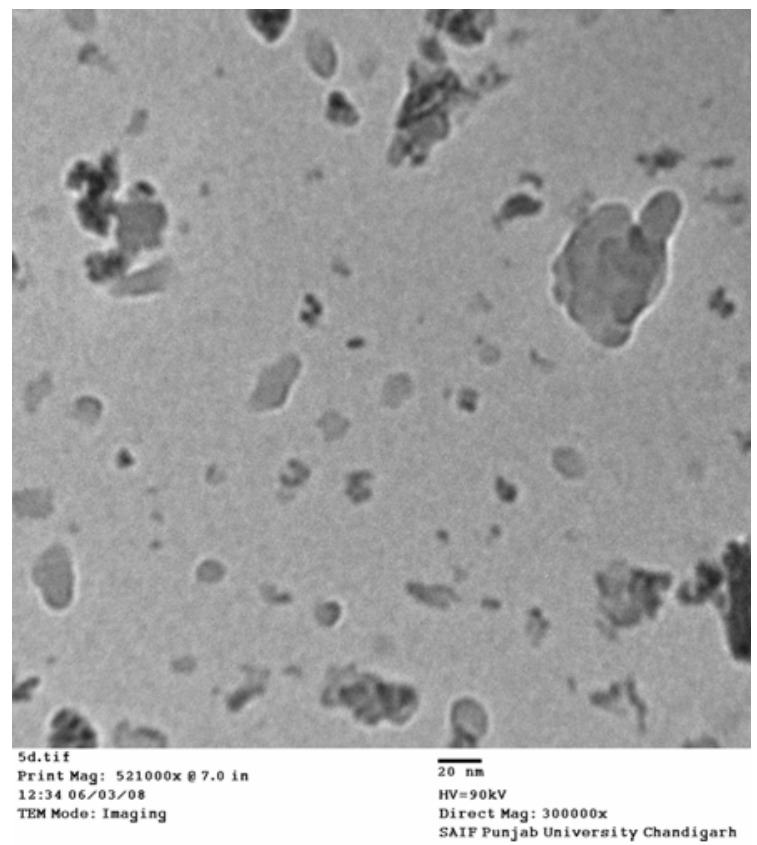

Figure 11. TEM Image of sample NT5.

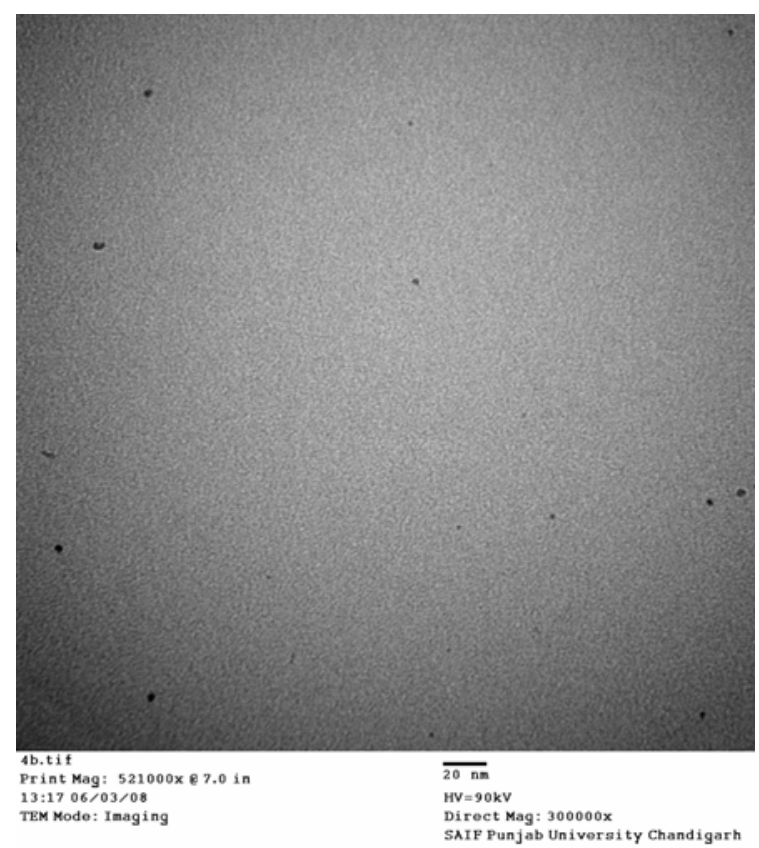

Figure 12. TEM image of sample NT19. 


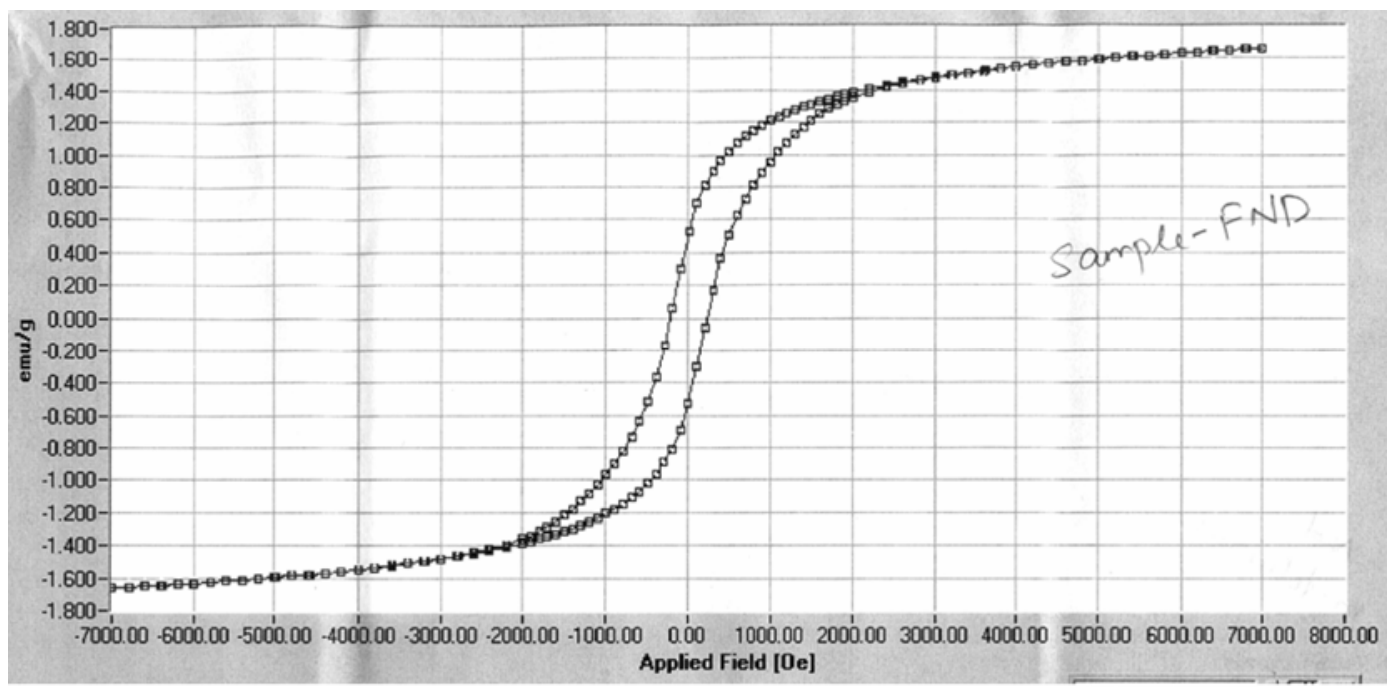

Figure 13. Magnetic hysteresis loop of sample ND3

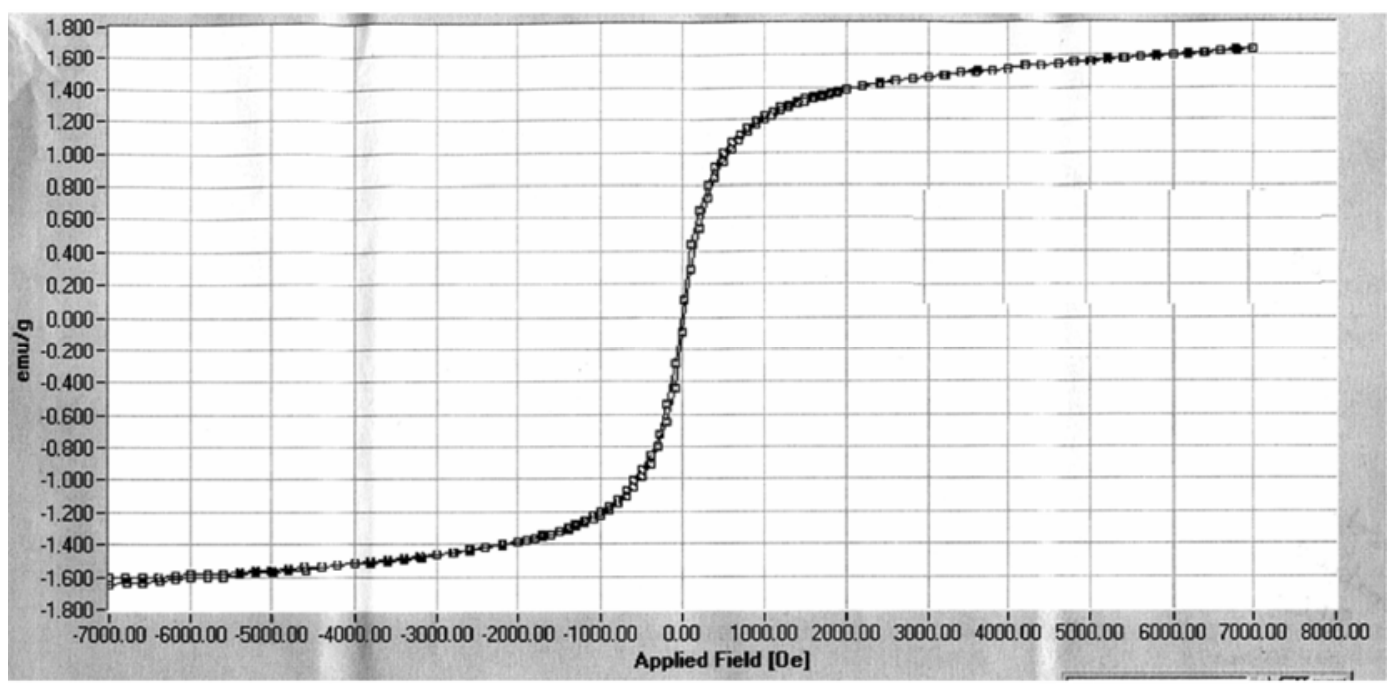

Figure 14. Magnetic hysteresis loop of sample NT7.

oxide particles are finely dispersed in the polymer matrix and are approximately spherical in shape within a narrow size range. However, in case of heating sample NT5 to $7000^{\circ} \mathrm{C}$ (NT19) (figure 12), the micrograph shows spherical particles with a particle size distribution of approximately 9-50 $\mathrm{nm}$. The residual part of the decomposed polymer can also be seen in the micrograph.

\subsection{Vibrating sample magnetometry studies}

The ferrites are solid-phase materials that constitute a combination of $\mathrm{Fe}_{2} \mathrm{O}_{3}$ with the oxides of other metals. They have special ferromagnetic, dielectric and semiconductor properties. Magnetic parameters were determined for samples ND3 and NT7 using vibrating sample magne- tometer (VSM) at room temperature. Figures 13 and 14 show the presence of a hysteresis loop at room temperature of the resultant nanocomposite of neodymium ferrite. The magnetization curve shows increase in magnetization with increasing field.

The values for coercivity $\left(H_{\mathrm{c}}\right)$ and saturation magnetization $\left(M_{\mathrm{s}}\right)$ obtained from the hysteresis loop are $23.91 \mathrm{Oe}$ and $3.01 \mathrm{emu} / \mathrm{g}$ and $22.42 \mathrm{Oe}$ and $2.99 \mathrm{emu} / \mathrm{g}$ respectively. The magnetization curve for the as-prepared nanocomposite exhibits ferromagnetic curve. The values for both $H_{\mathrm{c}}$ and $M_{\mathrm{s}}$ are lower as compared to reported values for bulk sample (Mishra et al 2004). The low values of $H_{\mathrm{c}}$ and $M_{\mathrm{s}}$ observed in nanocomposites is due to the existence of non-magnetic phase and non-magnetic medium because of dipole-dipole interactions, which contribute to magnetic anisotropy and consequently 
change the magnetic properties of nanoparticles ( $\mathrm{Li}$ et al 1998). Also, the small size of nanoparticles is responsible for low value of coercivity which gives rise to the formation of monodomain structure.

\section{Conclusions}

The chemical route using the copolymer matrix of aniline-formaldehyde has been very effective in the synthesis of nanocomposites of neodymium ferrites. The X-ray diffraction, ${ }^{57} \mathrm{Fe}$ Mössbauer and scanning electron microscopy show the formation of nanosized particle of neodymium ferrites in the polymer matrix. These studies further show the formation of solid solution of iron and neodymium oxide on heating the samples at temperatures ranging from $4000-7000^{\circ} \mathrm{C}$. From Mössbauer and X-ray diffraction studies, it is seen that $\gamma-\mathrm{Fe}_{2} \mathrm{O}_{3}$ which normally transforms into $\alpha-\mathrm{Fe}_{2} \mathrm{O}_{3}$ on heating up to $7000^{\circ} \mathrm{C}$, still persists in the samples containing neodymium ions. VSM studies indicate the superparamagnetic nature of the composites. Further, the infrared studies indicate that the polymeric backbone is strongly influenced by different reaction conditions and lead to variable magnetic characters in the heated samples.

\section{References}

Anderson A, Hunderi O and Granqvist C G 1980 J. Appl. Phys. 57754

Bahadur D 1992 Bull. Mater. Sci. 5432

Butterworth M D, Corradi R, Johal J, Lascelles S F, Maeda S and Armes S P 1995 J. Colloid Interface Sci. 174510

Greenwood N N and Gibb T C 1971 Mössbauer spectroscopy (London: Chapman and Hall Ltd) Ch. 10, p. 278
Jarjayes O, Fries P H and Bidan G 1995 Synth. Met. 69343

Johnson W C and Alexander J I D 1986 J. Appl. Phys. 592735

Josyulu O S and Sobhanadri J 1981 Phys. Stat. Sol. (a) 65479

Kladnig W F and Zenger M 1992 Modern ferrites: technologies and products (New York: United Nation International Development Organization)

Koch C J W, Madsen M B and Morup S 1986 Hyperfine Interact 28549

Li X G, Chiba A, Takahashi S and Sato M 1998 J. Appl. Phys. 833871

Maeda S and Armes S P 1994 Mater. Chem. 4935

Mathur R, Parihar M, Vadera S R and Kumar N 1998 Magn. Soc. Jpn. 22273

Mathur R, Sharma D R, Vadera S R and Kumar N 1999a Bull. Mater. Sci. 22999

Mathur R, Sharma, D R Vadera, Gupta S R, Gupta B B and Kumar N 1999b Nanostruct. Mater. 11677

Matutes-Aquino J, Diaz Castanon S, Mirabal-Garcia M and Palomares -Sanchez S A 2000 Scripta. Mater. 42295

Mishra D, Anand S, Panda R K and Das R P 2004 Mat. Chem. Phys. 86132

Pramanik P 1995 Bull. Mater. Sci. 18819

Sharma D R, Mathur R, Vadera S R, Kumar N and Kutty T R N 2003 J. Alloys Comp. 358193

Sinfelt J H 1977 Science 195641

Suri K, Annapoorni S and Tandon R P 2001 Bull. Mater. Sci. 24563

Suryanarayana C and Norton M G 1996 X-ray diffraction: A practical approach (New York: Plenum) p. 207

Vadera S R, Mathur R, Parihar M and Kumar N 1997a Nanostruct. Mater. 8889

Vadera S R, Tuli A, Kumar N, Sharma B B, Gupta S R, Chandra P and Kishan P 1997b J. Phys. IV, C7 1549

Viswanathan B 1990 Ferrite materials: science and technology (Delhi: Norosa Publishing House)

Xun L Y, Zhang H W, Liu Y L and Xiao J Q 2007 Chin. J Chem. Phys. 20739 